\title{
Contextual and behavioural factors influencing human-building interaction in university offices: a cross-cultural comparison
}

\author{
Simona d'Oca ${ }^{1, *}$, Dan Podjed ${ }^{2}$, Jure Vetršek ${ }^{2}$, Slavko Dolinšek ${ }^{2}$, Peter op't Veld ${ }^{1}$ \\ ${ }^{1}$ Huygen Engineers \& Consultants, Parkweg 22, 6212 XN Maastricht \\ ${ }^{2}$ Institute for Innovation and Development of University of Ljubljana, Kongresni trg 12, 1000 Ljubljana, Slovenia
}

\begin{abstract}
This paper presents the outcomes of a survey questionnaire deployed in the buildings of the Faculty of Economics (FE) and Faculty of Arts (FA) of the University of Ljubljana (UL), Slovenia, in a cross-cultural comparison of previous results gathered in three analogous university buildings in Italy. Objective of this study, which was in the Slovenian cases supplemented by qualitative (ethnographic) research approaches, is to provide comparative insights into four key research objectives: (1) cultural, contextual and socio-demographic factors regarding interaction with shared environmental controls (such as adjustable thermostats, operable windows, blinds and shades, and artificial lighting), (2) group dynamics such as perceived social norms, attitudes, and intention to share controls, (3) occupant's self-assessed ease of use and knowledge of how to operate control systems, and (4) occupant's perceived comfort, satisfaction, and productivity. First cross-country comparison analysis implies that practices and habits on how occupants interact within public buildings present distinct patterns within EU countries. More broadly, this study attempts to confirm the validity of the mixed methods research, combining quantitative and qualitative inquiry, and the survey instrument, as a way to validate the robustness of outcomes for future studies. In addition, the paper aims at illustrating why and how insights from different fields of social science, including psychology, sociology and anthropology, can foster innovation in the area of adoption and acceptance of technologies in shared spaces. The final objective of the study is enhancing attractiveness and effectiveness of ICT solutions for increasing user awareness and information provisions targeting energy savings, office workers' productivity and reduced operational energy costs, in the context of the EU H2020 MOBISTYLE project.
\end{abstract}

\section{Introduction}

Interdisciplinary research is essential for educating and informing building designers, engineers, social scientists, and policymakers on the multifaceted dimensions of designing and building energy-efficient systems and networks (Sovacool, 2014). Interdisciplinary research links two or more distinct scientific fields in an integrative way that combines the fields' frameworks, study designs, and methodologies to create a homogeneous perspective and pursue complex problems (Stephenson, 2010). Innovation in research and development is getting established around the understanding of the socio-technical link between building occupants' behaviour and the use of building technologies, energy services, and controls (Sovacool et al., 2015). This interdisciplinary approach can be described as a two-way exchange of knowledge from socio-technical disciplinary fields of science, in which:

"sociologists can provide more insight into macro-level factors that shape [...] energy use. Also, input from environmental scientists can be of valuable importance to further improve intervention studies. The environmental sciences can help translate energyrelated behaviours [...] into their environmental impact, e.g., in terms of $\mathrm{CO}_{2}$ emissions, and help select highimpact behaviours" (Abrahamse and Steg, 2011).

Advances in interdisciplinary research have emerged through the integration of the disciplinary frameworks, which were used to better understand human-building interactions from both the building physics and social sciences. Recent research (Frodeman, 2017) confirmed that while disciplinary theories contribute important understandings of the behavioural phenomena, blending aspects of interdisciplinary theories can provide additional interpretations and insights. In this picture, further research integrating multiple theories, comprehensively describing the energy-relevant humanbuilding interactions in office buildings based on the knowledge of interdisciplinary fields, will provide beneficial data. A research study (Von Grabe, 2016) postulated a systematic framework for the energy-related human-building contextual factors aiming to a synergetic organization of this interaction phenomena in buildings. Similar work (Wolske, Stern and Dietz, 2017) introduced an integrated framework that combines

\footnotetext{
* Corresponding author: s.doca@huygen.net
} 
variables from behavioural theories to explain consumers' interest in residential solar photovoltaic systems. Similarly, based on a theoretical framework integrating multiple theories and disciplines, researchers (Li, Menassa and Karatas, 2017) developed a survey instrument aiming to gather interdisciplinary knowledge on energy use behaviour in buildings. Li's study provided survey data on statistical models of occupant behaviours, useful to provide insights into occupant energy saving behaviour and characteristics as a function of motivation, opportunity, and ability to interact with building technologies. Importantly, Li's study also provides a useful suggestion for occupant interventions.

In the following sections, a set of theories that address the broader scope of social and building engineering contributions to the occupant behaviour literature is illustrated, including the Social Cognitive Theory (Bandura, 1986), the Theory of Planned Behaviour (Ajzen, 1991), Theory of Practice (Shove, 2003), as well as the Actor-Network Theory (Latour, 1994) and the Attitude-Behaviour-Context (A-B-C) model (Abrahamse and Steg, 2009). Even though these theories are often conflicting, we attempt to find the middle ground and pragmatically use them in the context of our study.

Ethnography is the most commonly used method of anthropology and has become more prominent in several other fields of social science, including sociology and psychology. Its conventional primary technique of inquiry is participant observation, in which "the researcher takes part in the daily activities, rituals, interactions, and events of a group of people as one of the means of learning the explicit and tacit aspects of their life routines and their culture" (DeWalt and DeWalt 2000). This method is often supplemented by interviews, focus groups and other ways of collecting information directly from people in their everyday settings. In its traditional form, ethnographic research (fieldwork) lasts from 12-18 months. Transferred to business and industry settings, ethnography has proved to be highly valuable, but has often been perceived as time- and resourceconsuming, or non-generalizable due to its focus on individuals and small group (Jordan and Dalal 2006).

\subsection{Purpose of the Study}

In the context of this study, we decided to upgrade the ethnographic (qualitative) findings by quantitative results, collected by surveys among people working in buildings, since the combination of research approaches enabled us to get a better overview of how and why people interact with buildings. The mixed methods research (e.g., Brannen 2005; Cresswell and Plano Clark 2011; Morgan 2014; Morse and Niehaus 2009; Teddlie and Tashakkori 2009) was thus used for recording and analysing behaviours, connected to use of buildings. In addition, we emphasised the need for circular research design, where we tried not only to mix the methods, but to traverse between them to continually verify and enhance qualitative findings by quantitative results and another way around. Such circularity provides in our opinion research flexibility and enables shifting perspectives in response to information collected in the field, i.e. by participant observation, or from surveys and other quantitative approaches (Pretnar and Podjed 2018). Supplemented by qualitative (ethnographic) research approaches, main purpose of this study is to provide cross-country comparative insights into four key research objectives: (1) cultural, contextual and sociodemographic factors regarding interaction with shared environmental controls (such as adjustable thermostats, operable windows, blinds and shades, and artificial lighting), (2) group dynamics such as perceived social norms, attitudes, and intention to share controls, (3) occupant's self-assessed ease of use and knowledge of how to operate control systems, and (4) occupant's perceived comfort, satisfaction, and productivity.

First cross-country comparison analysis implies that practices and habits on how occupants interact with public buildings present distinct patterns within EU countries. More broadly, this study attempts to confirm the scientific validity of the mixed methods research, combining quantitative and qualitative inquiry, and the survey instrument, as a way to validate the robustness of outcomes for future studies. In addition, the paper aims at illustrating why and how insights from different fields of social science, including psychology, sociology and applied anthropology, can foster innovation in the area of adoption and acceptance of technologies in shared spaces.

In this paper, we highlight the findings of the survey. However, all the presented results and themes were discussed and validated with participants of the longterm qualitative (ethnographic) study, carried out in the Slovenian case. Therefore, results are given in Section 3 and the interpretation of the cross-country comparison are discussed in Section 4. Discussion are based on the combination of methods, i.e. qualitative and quantitative study, together with the higher integration of the ethnographic insights, which all mutually influenced and informed each other.

\section{Methodology}

In previous correlated studies (D’Oca et al 2016, 2017), the authors developed a research framework synthesizing building physics with social science for studying humanbuilding interaction in university office settings (D'Oca et al 2018). The interdisciplinary nature of the framework is based on the adoption of building physics and societal theories explaining the environmental and cognitive processes underpinning the comfort-related human-building interaction in shared office settings. The Drivers-Needs-Actions-Systems (DNAS) framework (Hong et. al, 2015) is chosen for rationalizing comfortrelated adaptive behaviours in buildings. The Social Cognitive Theory (SCT) from Bandura is selected as a general theory explaining the environmental, cognitive, and behavioural factors influencing the human decisionmaking process in social contexts. Based on the proposed research framework, a survey questionnaire 
has been designed consisting of 37 questions (D'Oca et al 2017, 2018). Measures of the variables are made either through Likert-type scales (i.e., Fanger's 7-point comforts scale or 5-point scale where 1 typically indicates strong disagreement and 5 strong agreement) or control questions.

\subsection{The Italian Study}

Every survey question in the Italian questionnaire was implemented within the Qualtrics Software (https://www.qualtrics.com/it/) environment and represents one or more independent variables, correlated with a variable ID, to articulate the measures of the investigation. Each survey response was recorded through the Qualtrics software together with the date of compilation and geographical coordinates of the University Institution. To meet data-privacy requirements, the survey remained anonymous and no personal identification or sensitive data are collected. The survey questionnaire was validated in three university institutions across Italy located in Turin (Polito), Perugia (UniPg), and Rende (UniCal). Further description of the Italian university buildings and climatic locations can be found in D'Oca et al 2017.

The targets for the proposed survey were administrative staff, faculty members, and students that regularly occupy their working space. The Qualtrics survey link was sent to the sample through the institutional e-mailing list of the three Universities (Polito, UniPg, UniCal) over a period of four weeks during the spring season (from April 5th to May 8th, 2017). Three reminders were sent to the participants at the end of each week. A total number of 1160 valid responses were collected from the online questionnaire (Table 1). Despite incentives (see Section 4.2), the response rate was low (between 11\% and $16 \%)$.

Table 1. Response Rate in the Italian Survey

\begin{tabular}{cccc} 
& $\begin{array}{c}\text { PoliTo - } \\
\text { Turin }\end{array}$ & $\begin{array}{c}\text { UniPg - } \\
\text { Perugia }\end{array}$ & $\begin{array}{c}\text { UniCal - } \\
\text { Rende }\end{array}$ \\
\hline Total Valid & 502 & 405 & 253 \\
\hline $\begin{array}{l}\text { Total Sent } \\
\text { Response } \\
\text { Rate }\end{array}$ & 4424 & 2991 & 1598 \\
\hline
\end{tabular}

Gender of respondents was almost equally distributed (50\% male and 48\% female). Respondents are most frequently full-time employees (with 31-40 hours workspace occupancy), who typically occupy shared or private offices $(33 \%)$, or shared open offices $(30 \%)$. Cubicle spaces are seldom used in the sample $(2 \%)$. Significantly, single private offices emerge typically occupied by men $(61 \%)$ in the range $40-61$ years old, and less frequently by women $(37 \%)$ or younger people in the range $18-28$ years old $(1 \%)$. The majority of the sample population holds a $\mathrm{PhD}$ or master's degree $(41 \%)$, or a master's or an equivalent five-year degree $(36 \%)$.

\subsection{The Slovenian Study}

The questionnaire, translated to Slovenian language, was first sent by email to the management of both faculties at the University of Ljubljana, i.e. Faculty of Arts (UL FA) and Faculty of Economics (UL FE). The management staff then distributed it by institutional mailing lists to all employees at both faculties. The email, received by people, included an introductory explanation regarding the study and a link to the survey prepared in $1 \mathrm{ka}$ system (https://www.1ka.si/uporabniki-stavbe).

First, the questionnaire was shared at the Faculty of Arts on 11 June 2018 to 624 employees, with a reminder sent out 14 days later. We received 123 (19.7\%) filled out questionnaires, suitable for further analysis. At the FE, the questionnaire was sent out on 22 June 2018 to 250 employees, out of which $71(28.4 \%)$ replied and filled out the form. In total, we received 250 replies; 194 out of 874 distributed in total at both faculties were correctly filled out and suitable for further analysis $(22.2 \%) ; 56$ questionnaires were not appropriately filled out - most of those were not entirely finished.

Study purposes and results were discussed before, during and after the study with management, employees and energy managers of both faculties. The unstructured interviews provided us with additional information for explaining the situation in both cases from Slovenia. Such qualitative research approaches were a part of a broader ethnographic study, carried out in the MOBISTYLE project (https://www.mobistyleproject.eu/), which involved interviews, focus groups and participant observation at both faculties in Slovenia. The qualitative study supplemented the quantitative research, which is the basis of this article; findings of the study were later checked in the "field" and among people using both faculty buildings and working in offices.

\subsection{The Slovenian Buildings}

Both buildings are made of reinforced concrete and are insulated. The buildings have flat roofs. UL FE building is partly positioned underground. The retrofit covered optimization of HVAC and lighting systems, BMS upgrade and windows heat bridges minimization. The UL FA is a monolith 6-story building, also partly positioned underground. Retrofit covered thermal insulation of façade, replacement of some windows, lighting optimization, HP installment and BMS upgrade.

At the UL FE, built in 1980, heating is delivered by a district heating company. Heat is distributed by warm air, radiators and convectors, depending on the room type. There are 12 larger ventilation systems (AHU) on site. Reversible HP and additional chillers are used for cold generation. PV power plant $(105 \mathrm{kWp})$ is installed on the roof. HW is prepared in the substations by heat exchangers. The building has its own high-voltage connection point. 
At the UL FA, built in 1960, heating is also delivered by a district heating company. Heating is enabled mainly by radiators in combination with warm air (several AHUs). A small heat pump is installed in the energy station. There is no central HW preparation. Chillers are installed on the roof. The building has its own highvoltage connection point.

\section{Results}

Compared to state-of-the-art literature in the field, this work brings innovation in interdisciplinary survey methods and cross-country knowledge on humanbuilding interactions in the workspace. The innovative research method used in this survey questionnaire is grounded in an interdisciplinary framework merging building physics and social science insights on the energy- and comfort-related human-building interaction in the workspace. By adopting this socio-technical framework in a cross-country context, analyses of more than 1000 collected responses on self-reported behavioural intention, attitudes, social norms, as well as perceived behavioural control, comfort, satisfaction, and productivity illustrated why and how social science insights, in tandem with building physics theories, can bring innovative knowledge into the understanding of office workers' interactions with building technologies to control their indoor environment.

\subsection{Key takeaways from the Italian Survey}

Results of the Italian survey questionnaire provided insights into four key learning objectives, as follows:

I. Regarding individual's motivational drivers in interacting with shared building environmental controls: office workers open windows primarily to introduce fresh air into space; they typically close windows because the indoor temperature is perceived as too cold or too warm. Window blinds and shades are more frequently pulled up or opened to let more daylight in the office space, while they are drawn mainly to reduce glare on the computer screens or workspace. Thermostat set points and lighting systems are generally regulated to restore comfort conditions in the workspace (because the temperature is perceived as too hot or too cold or to adjust lighting levels in the room) and less frequently as a consequence of an energy conservation behaviour.

II. Regarding group dynamics: the intention to share controls does not emerge correlated to perceived comfort, satisfaction, productivity, and knowledge on how to use technology, but rather as a behavioural trait of the occupant. Shared control of the indoor environment in the office space is generally perceived as a fair or good thing across all the climate zones, highlighting a common positive attitude of office workers towards sharing control devices. Occupants in the Northern region (Turin) tend to report a stronger subjective norm on the co-workers' expectation to share control over the indoor environmental quality.

III. Regarding perceived behavioural control of building technologies (ease of usage and knowledge): office workers tend to perceive greater ease of sharing control of operable windows, lighting systems, and blinds and shades than thermostat settings. Similarly, respondents appear to be more acquainted with the use of windows, blinds, shades, and artificial lighting then the regulation of thermostats in their workspace. Consequently, a general dissatisfaction over the shared control of the thermostat settings in office spaces emerges.

IV. Focusing on perceived comfort, satisfaction, and productivity, office workers tend to appear more satisfied with the quality of natural and artificial lighting than indoor temperature and indoor air. Natural and artificial lighting seems to predominantly influence productivity, while variables such as indoor temperature and indoor air are more frequently perceived as responsible for the loss of productivity. Perceived comfort emerged to be correlated with satisfaction and productivity, and less correlated with the ease of use and knowledge of control, as well as attitudes and subjective norms.

\subsection{Key takeaways from the Slovenian Survey}

In our descriptive analysis we included only variables where our survey showed statistical significance. In questions not included in the document, there was no statistically significant difference. As it can be seen in Figure 1, the air temperature has a significant negative impact on the satisfaction of people working in offices; $43.3 \%$ of respondents are very or somewhat unsatisfied at UL FE and $50.5 \%$ at UL FA.

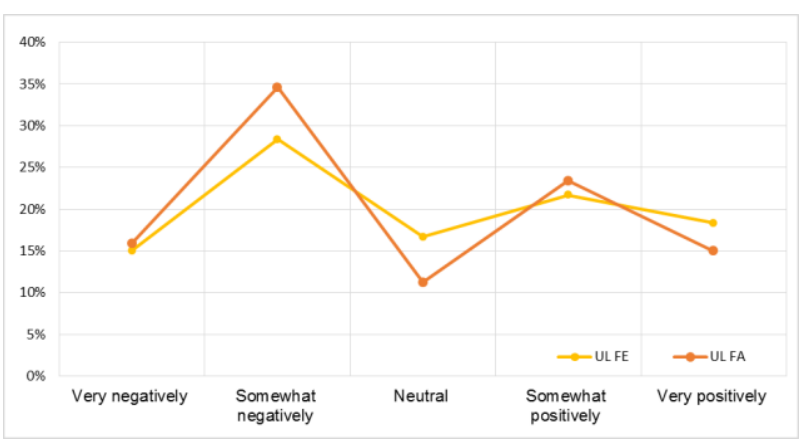

Figure 1. Satisfaction with indoor temperature.

Satisfaction with indoor air quality, presented in Figure 2, seems to be more important at UL FA, where we received more negative and less positive responses regarding the topic. The negative feedback could be caused by more people working in the offices at UL FA. 


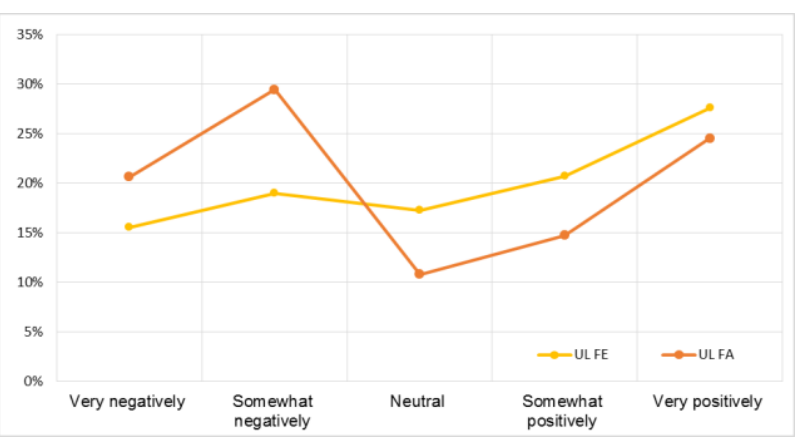

Figure 2. Satisfaction with indoor air quality.

As it can be seen in Figure $340 \%$ of people at UL FE and only $10.9 \%$ of people working at UL FA have private closed offices.

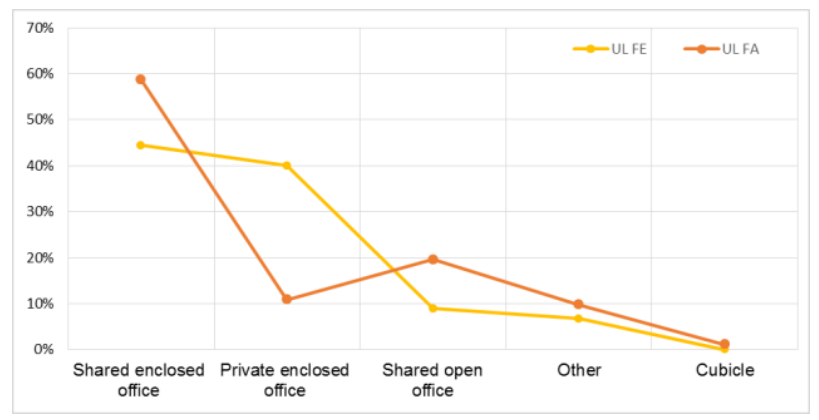

Figure 3. Workspace types in Slovenian cases.

Figure 4 shows high satisfaction rate with natural lighting at both researched faculties. The positive feedback could be associated with the fact that there are no offices without windows in the Slovenian cases. Both at the UL FA and UL FE there are lecture rooms in the basement of the faculty buildings; however, they are mainly used by students who were not included in this study.

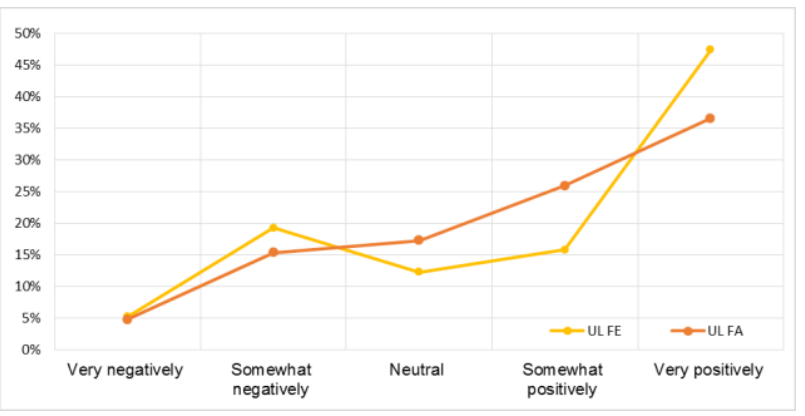

Figure 4. Satisfaction with natural lighting.

On the other hand, satisfaction with artificial lighting is much worse at UL FA; $41.4 \%$ of respondents are very or somewhat unsatisfied, as it can be seen in Figure 5. According to our qualitative inquiry (informal interview with the energy manager at UL FA), an important reason for such feedback is that the lighting systems in the offices of the UL FA are over 20 years old. There are tube fluorescent lamps installed in offices, which often blink before braking and are overall in bad condition.

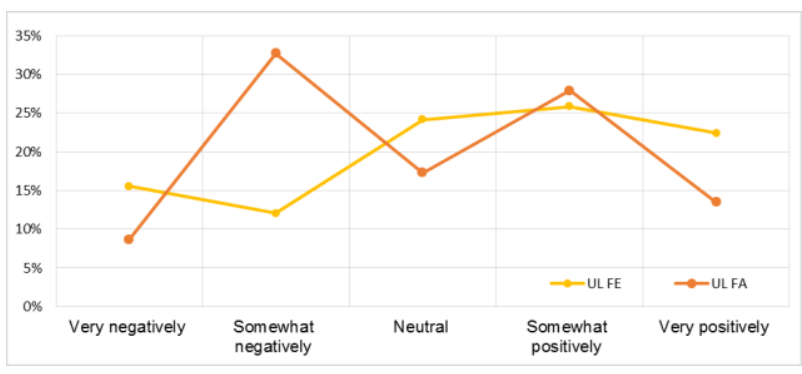

Figure 5. Satisfaction with artificial lighting.

As seen in Figure 6, people working at UL FA are more dissatisfied and less satisfied then UL FE concerning the acoustic environment. According to an informal interview with the faculty management, the reason is that the UL FA is located next to a busy road, which influences people working in offices.

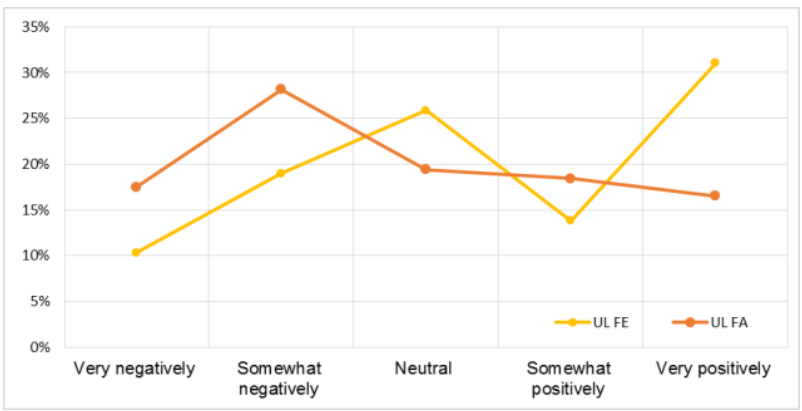

Figure 6. Satisfaction with acoustics quality.

Figure 7 shows that more than half (52.6\%) of the people at UL FA noticed that temperature would have very or somewhat negative influence on their productivity at work. On the contrary, at UL FE $28 \%$ of people noticed that temperature has a very positive impact on productivity.

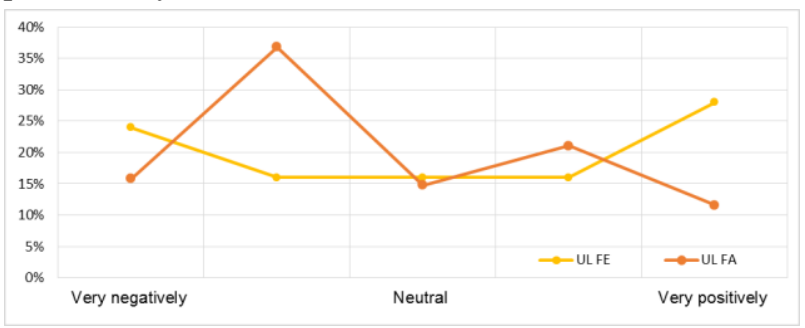

Figure 7. Influence of indoor quality on productivity.

Figure 8 shows the perceived influence of indoor air quality on productivity is significantly more negative and less positive at UL FA. The reason could be again correlated with more people working together in offices, as seen in Figure 3 and Figure 4.

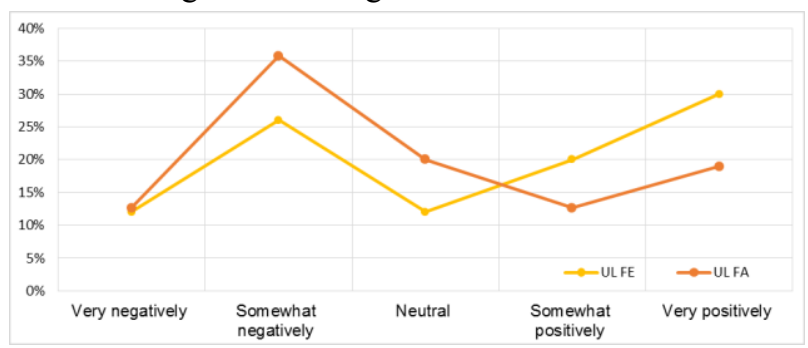

Figure 8. Influence of indoor air quality on productivity. 
Regarding the productivity and artificial lights quality, shown in Figure 9. responses of people working at UL FA are much more neutral than on UL FE, where there were more very negative and very positive responses.

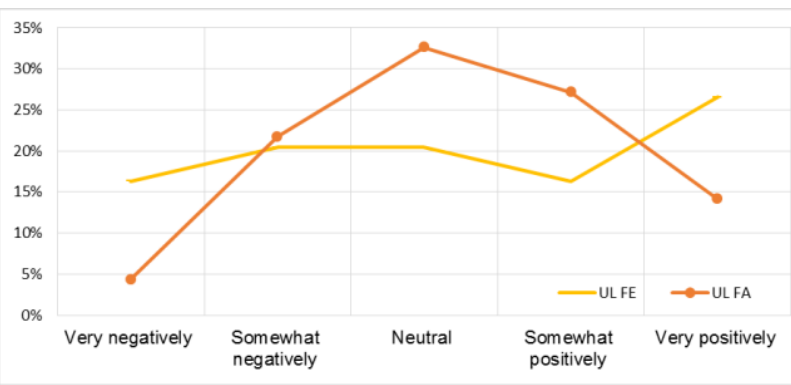

Figure 9. Influence of artificial lighting on productivity.

Sources of thermal discomfort, presented in Figure 10, are similar at UL FE and UL FA. The majority of people claim that their workspace is hotter than other areas; according to our qualitative inquiry, the main reason standing behind their feedback could be the time of sending the questionnaire, when the cooling season began.

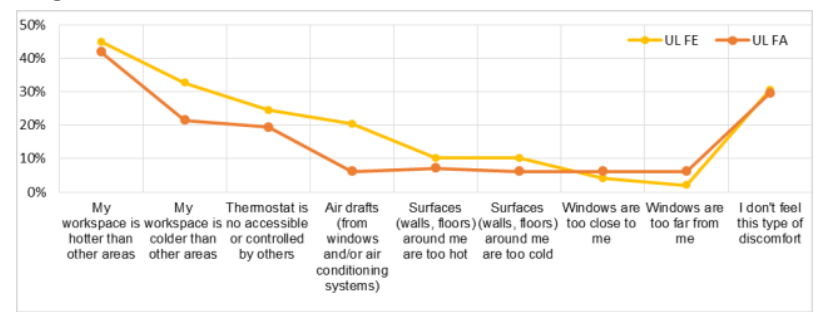

Figure 10. Main sources of thermal discomfort at work.

There are apparent issues with air quality discomfort at work, shown in Figure 11, only 28.6\% (UL FE) and $21.4 \%$ (UL FA) of people do not feel this type of discomfort, out of which the stale air is the worst example.

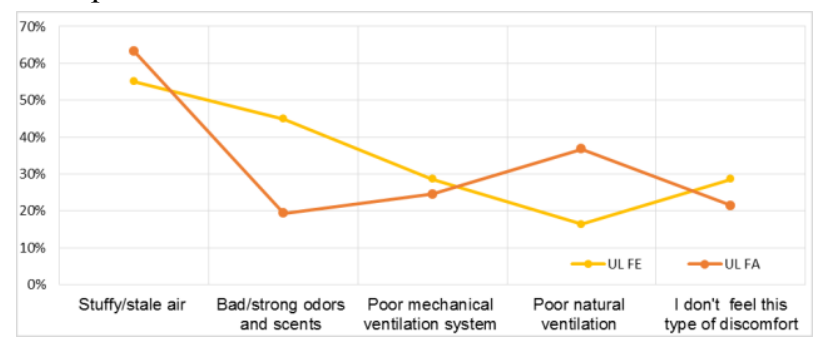

Figure 11. Sources of air quality discomfort at work.

This might be connected with the main reason for opening windows, as shown in Figure 12, where the majority of people both at UL FA and UL FE explained they open their office windows in spring to get fresh air.

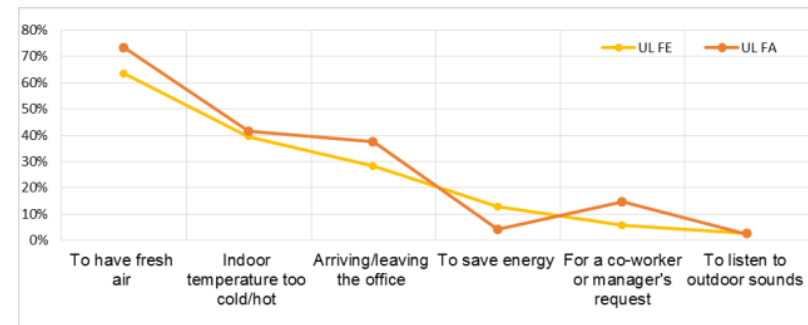

Figure 12. Reasons for opening windows at work in spring.
As shown in Figure 13, the main reason for closing windows in spring is to reduce the noise coming from the surroundings of the building. The rate is higher on UL FA, which is located next to a busy road. At the UL $\mathrm{FE}$, the source of noise might be students spending time in the surroundings, which was noticed during our participant observation as part of the qualitative study.

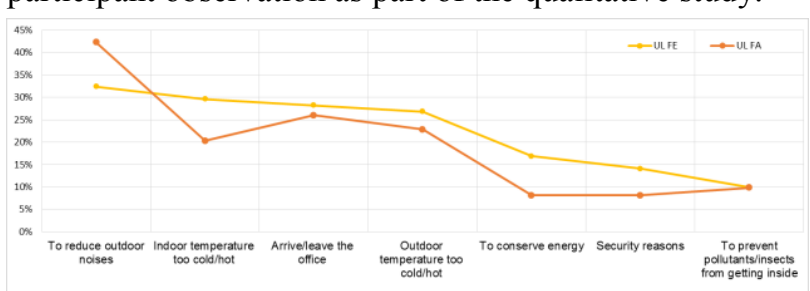

Figure 13. Reasons for closing windows at work in spring.

The main reason for opening shades in summer, as seen in Figure14, is to let more daylight in office; the main reason for closing them, as presented Figure 14, is to reduce glare on someone's computer screen or in general in the workplace.

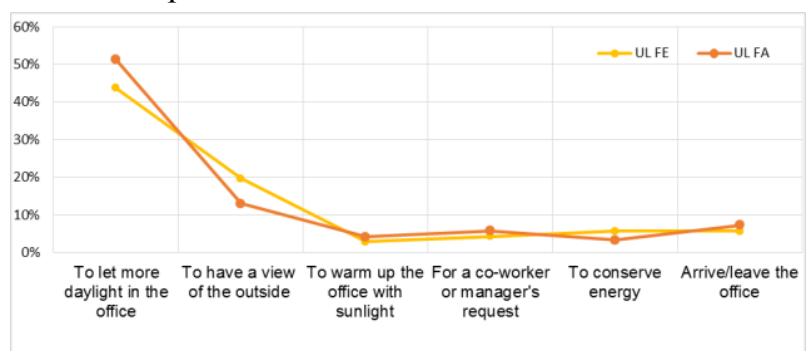

Figure 14. Reasons for opening shades in summer.

It is somewhat surprising, as seen in Figure 15, that the second most relevant reason for closing shades is to reduce overheating of workplace and office due to direct sunlight, meaning that people are apparently aware of the correlation between sunlight and thermal comfort in rooms.

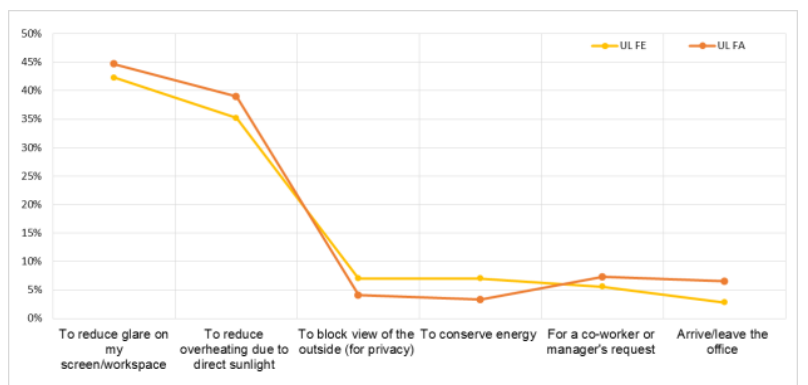

Figure 15. Reasons for closing shades in summer.

\section{Discussion}

Interestingly, Figure 16 shows Slovenians appear to be generally more outspoken when it comes to expressing a thermal sensation, with fewer responses gathering around the neutral thermal zone compared to the Italian respondents Also, smartly designed buildings emerge providing higher perceived easiness for interacting with the central system (i.e. windows), in the workspace. 


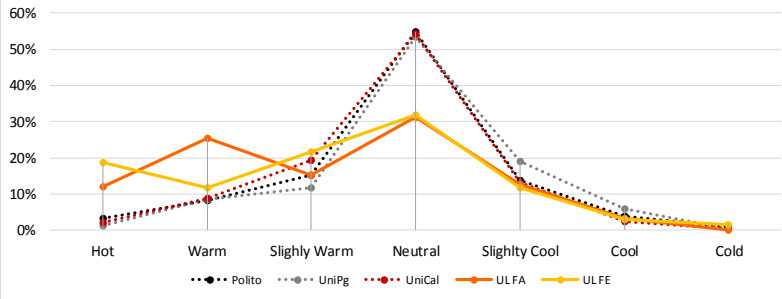

Figure 16. Comparison of the perceived thermal sensation between the Italian and the Slovenian survey

The same trend emerged for the control of artificial lighting, shades and thermostatic valves (Figure 17).

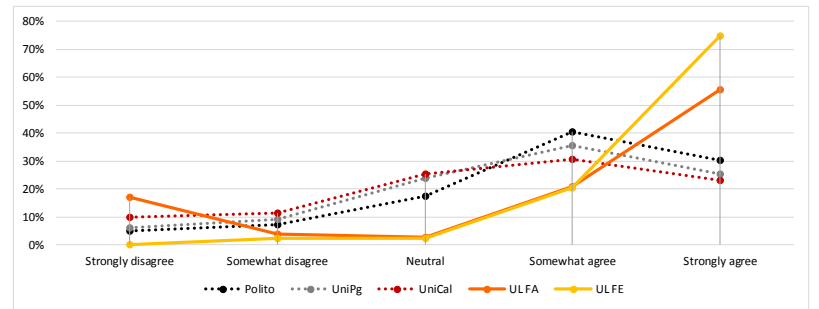

Figure 17. Comparison of perceived ease of opening windows between the Italian and the Slovenian Survey

Similarly, (Figure 18) smart buildings emerge providing higher perceived knowledge on how to operate control systems, such as artificial blinds or thermostat, compared to traditional office building settings (such as the ones of the Italian Universities.)

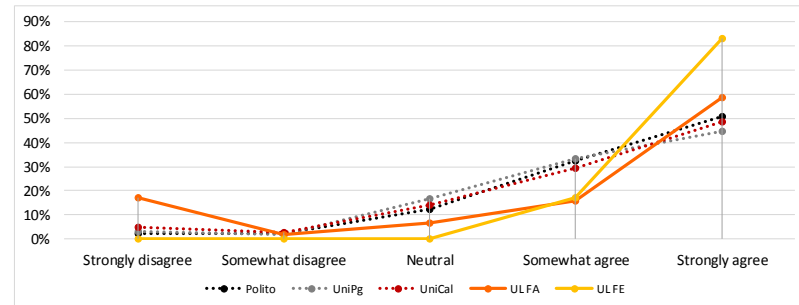

Figure 18. Comparison of perceived knowledge on how to operate shades or blinds between the Italian and the Slovenian survey

\section{Conclusions}

When it comes to dealing with human-building interaction in the office environments, many are still the open questions the research and engineering community are facing. Primary, basic statistics on both independent and dependent variables triggering operation of control systems must include the consideration of typical behavioural patterns, subject demographics, the presence of shared controls, as well as concepts of self-assessed comfort and productivity. Further investigation is still needed in this direction, for instance, to understand whether shared control settings, such as open working spaces influence productivity and satisfaction, with a cross country comparison, and to which extent. By using, for instance, regression-based analysis, research can help to isolate the most important social, personal and environmental factors influencing the satisfaction with shared controls and settings.
Large interest is emerging among the research community (see Annex 66 final report), towards the relationship between behavioural patterns (window control behaviour, thermostat control behaviour and others) and specific characteristics of the country (e.g. climate, work culture). Our research aims to highlight findings for aggregating some of the countries with similar characteristics and also similar patterns with respect to others. However, it might be necessary to discuss if variations among countries are really due to the specific characteristics of the context, culture and "ecological" settings, or if they are more related to the specific context such as building, systems and controls. Also, it would be interesting to further investigate whether the study of the office environment in universities can be extended to a general notion of offices. By using quali-quantitative research methods, we are aiming to drive the future development of sociotechnical research aiming to provide answers and solutions supporting the innovative development of future productive, comfort and healthy workspace.

This work set the foundation to extrapolate knowledge on how do social norms vary across countries, the existence of any relevant relationship between group negotiation and social and personal norms, perceived control, and satisfaction of control. Interestingly, we found group negotiation dynamics and the intention to share control vary between different office types. Which factors of the human-building interaction do actually influence productivity at work, is still our core research question. Comparison with existing objective findings, including the analysis of the relationship between available control, perceived control and satisfaction of control are the pillars that will hopefully provide the needed answer in future works. To do so, investigation on comfort, productivity and satisfaction must eventually be linked to outdoor and extrinsic environmental conditions during the compilation of the survey, although this is a time consuming and not an exhaustive evaluation of the numerous and stochastic factors prompting human-building interaction in offices spaces.

Potential future research must focus on the attitudes of occupants towards "smart buildings" versus older buildings (are the "smart buildings" worth the economic and technical investment?), as well as on the most relevant drivers making people take their decisions, when it comes to seeking and regulating their comfort zone, in shared environments. Forthcoming research must identify aspects that are generally similar in each country, and therefore, the need to collect (and protect) data in new geographically relevant locations will become necessary. This will lead to identifying areas that are intrinsically different (for context, culture, climate, socio-economical background, etc), and therefore to the necessity to collect data on in future studies in order to have appropriate representation of occupants (such as group versus social norms, knowledge and usage patterns). 
Drawing some considerations about our experience, it is important to mention the importance of the preparation phase of the questionnaire, the issues related to the translation in different languages, and the contemporaneity of the survey in diverse countries, which remain in our opinion the most critical points. In its whole, this paper aimed to contain a comparative description of the survey study conducted in different universities, including the classification from the climatic, structural and constructive point of view. In fact, many questions (and consequently the answers) on human-building interaction in office settings remain strongly correlated to intrinsic characteristics of buildings and their location.

\section{Acknowledgments}

The survey questionnaire was designed and tested as part of the activities conducted among the international research community embracing the International Energy Agency, Energy in Buildings and Communities Programme, Annex 66, "Definition and Simulation of Occupant Behaviour in Buildings." This work was supported by the Assistant Secretary for Energy Efficiency and Renewable Energy of the United States Department of Energy under Contract No. DEAC02-05CH11231.

The methodology for the ethnographic study partly developed in the EU Erasmus+ Knowledge Alliance project PeopleCentred Development Approaches in Practical and Learning Environments (PEOPLE), contract No. 574832-EPP-1-2016-1SI-EPPKA2-KA, and the EU Horizon 2020 MOBISTYLE project (H2020-EE07-2016).

Finally, we thank the administrations at the University of Ljubljana's Faculty of Arts (UL FA) and Faculty of Economics (UL FE) for enabling and supporting the study.

\section{Reference}

1. Abrahamse, W., \& Steg, L. Factors Related to Household Energy Use and Intention to Reduce It: The Role of Psychological and Socio-Demographic Variables. Human ecology review, 18(1), 30-40. (2011).

2. Ajzen, I. The theory of planned behavior. Organizational Behavior and Human Decision Processes, 50, 179-211. (1991).

3. Bandura A., Social foundations of thought and action: A social cognitive theory. Prentice-Hall, Inc., Englewood Cliffs, NJ, US (1986)

4. Brannen, Julia. Mixing Methods: The Entry of Qualitative and Quantitative Approaches into the Research Process. International Journal of Social Research Methodology 8 (3): 173-184 (2005).

5. Creswell, John W., and Vicki L. Plano Clark. Designing and Conducting Mixed Methods Research. Los Angeles, CA: Sage (2011).

6. DeWalt, Kathleen M., and Billie R. DeWalt. Participant Observation. In Handbook of Methods in Cultural Anthropology, ed. H. Russell Bernard. Walnut Creek etc.: Altamira Press. 259-299 (2000).

7. D’Oca S., Corgnati S., Pisello A.L., Hong T., Introduction to an occupant behavior motivation survey framework. Proceeding of the Clima 2016 Conference (2016).
8. D'Oca S, Chen C.F., Hong T., Synthesizing building physics with social science: An interdisciplinary framework for context and behavior in office buildings, Energy Res. Soc. Sci. (2017).

9. D’Oca S, Pisello A.L., De Simone M, M. Barthelmes V., Hong T., Corgnati S.P. Human-building interaction at work: Findings from an interdisciplinary cross-country survey in Italy. Building and Environment 132 (132): 147159 (2018).

10. Hong H., D’Oca S., Taylor-Lange S.C., Turner W.J.N., Chen Y., Corgnati S.P., An ontology to represent energyrelated occupant behavior in buildings. Part II: Implementation of the DNAS framework using an XML schema, Build. Environ. 94: 196-205 (2015).

11. Frodeman, R., Klein, J. T., \& Pacheco, R. C. D. S. The Oxford handbook of interdisciplinarity. Oxford University Press (2017).

12. Jordan, Brigitte, and Brinda Dalal. Persuasive Encounters: Ethnography in the Corporation. Field Methods 18 (4): 1-24 (2006).

13. Da Li, Carol C. Menassa, Aslihan Karatas. Energy use behaviors in buildings: Towards an integrated conceptual framework. Energy Research \& Social Science (23): 97112 (2017).

14. Morgan, David L. 2014. Integrating Qualitative and Quantitative Methods: A Pragmatic Approach. Los Angeles (CA): Sage.

15. Morse, Janice M., and Linda Niehaus. 2009. Mixed Methods Design: Principles and Procedures. Walnut Creek (CA): Left Coast Press.

16. Pretnar, Ajda, and Dan Podjed. 2018. Data Mining Workspace Sensors: A New Approach to Anthropology. In Language Technologies and Digital Humanities 2018 Conference Proceedings, eds. Darja Fišer and Andrej Pančur. 227-233.

17. E. Shove, Comfort, cleanliness and convenience: the social organization of normality. Berg Publishers, Oxford and New York (2003)

18. Sovacool, B.K. What are we doing here? Analyzing fifteen years of energy scholarship and proposing a social science research agenda. Energy Research and Social Science, 1: 1-29 (2014).

19. Sovacool, B.K., Ryan, S.E., Stern, P.C., Janda, K. Rochlin, G., Spreng, D., Pasqualetti, M.J., Wilhite, H., Lutzenhiser, L. Integrating social science in energy research. Energy Research \& Social Science, 6: 95-99 (2015).

20. Stephenson, J., Lawson, R., Carrington, G., Barton, B., Thorsnes, P., \& Mirosa, M. The practice of interdisciplinarity. The International Journal of Interdisciplinary Social Sciences, 5(7), 271-282 (2010).

21. Teddlie, Charles, and Abbas Tashakkori. Foundations of Mixed Methods Research: Integrating Quantitative and Qualitative Approaches in the Social and Behavioural Sciences. Thousand Oaks: Sage (2015)

22. Von Grabe J., The systematic identification and organization of the context of energy-relevant human interaction with buildings - A pilot study in Germany, Energy Res. Soc. Sci. 12: 75-95 (2016)

23. Kimberly S. Wolske, Paul C. Stern, Thomas Dietz. Explaining interest in adopting residential solar photovoltaic systems in the United States: Toward an integration of behavioral theories. Energy Research \& Social Science (25): 134-151 (2017). 